\title{
Lateral inhibition of Notch signaling in neoplastic cells
}

\author{
Kah Jing Lim ${ }^{1, *}$, William D. Brandt ${ }^{1, *}$, Jason A. Heth ${ }^{4}$, Karin M. Muraszko ${ }^{4}$, \\ Xing Fan ${ }^{4,5}$, Eli E. Bar ${ }^{1,6}$, Charles G. Eberhart ${ }^{1,2,3}$ \\ ${ }^{1}$ Department of Pathology, Johns Hopkins University, Baltimore, MD 21231, Maryland, USA \\ ${ }^{2}$ Department of Oncology, Johns Hopkins University, Baltimore, MD 21231, Maryland, USA \\ ${ }^{3}$ Department of Ophthalmology, Johns Hopkins University, Baltimore, MD 21231, Maryland, USA \\ ${ }^{4}$ Department of Neurosurgery, University of Michigan, Ann Arbor, MI 48109, Michigan, USA \\ ${ }^{5}$ Department of Cell and Developmental Biology, University of Michigan, Ann Arbor, MI 48109, Michigan, USA \\ ${ }^{6}$ Department of Neurological Surgery, Case Western University, Cleveland, $\mathrm{OH} 44106$, Ohio, USA \\ *These authors have contributed equally to this work \\ Correspondence to: \\ Charles G. Eberhart, e-mail: ceberha@jhmi.edu \\ Keywords: Notch, lateral inhibition, cancer, signaling \\ Received: October 24, $2014 \quad$ Accepted: November 17, $2014 \quad$ Published: February 13, 2015
}

\section{ABSTRACT}

During normal development, heterogeneous expression of Notch ligands can result in pathway suppression in the signal-sending cell, a process known as lateral inhibition. It is unclear if an analogous phenomenon occurs in malignant cells. We observed significant induction of Notch ligands in glioblastoma neurospheres and pancreatic carcinoma cells cultured in low oxygen, suggesting that this phenomenon could occur around hypoxic regions. To model lateral inhibition in these tumors, the ligand Jagged 1 was overexpressed in glioblastoma and pancreatic carcinoma cells, resulting in overall induction of pathway targets. However, when ligand high and ligand low cells from a single line were co-cultured and then separated, we noted suppression of Notch pathway targets in the former and induction in the latter, suggesting that neoplastic lateral inhibition can occur. We also found that repression of Notch pathway targets in signal-sending cells may occur through the activity of a Notch ligand intracellular domain, which translocates into the nucleus. Understanding how this neoplastic lateral inhibition process functions in cancer cells may be important in targeting ligand driven Notch signaling in solid tumors.

The Notch pathway is active and functionally important in a wide range of tumors, including hematopoietic neoplasms [1, 2], melanoma [3], and carcinomas of the breast [4, 5], ovary [6], lung [7], prostate [8], and pancreas [9]. In many of these tumors, Notch is believed to play key roles in the specification, proliferation and survival of treatment-resistant cancer stem cells [10-12]. Understanding how Notch signaling is initiated and maintained is therefore critical for effective therapeutic intervention in a range of tumor types.

In non-neoplastic contexts, Notch activity is initiated when ligands from the Jagged (JAG) and Delta-like families on one cell bind to Notch receptors on an adjacent cell. The receptors on the cell surface are processed through two sequential cleavages. First, the ADAM family of secretases cleaves the receptor to produce the Notch
C-terminal fraction. Next, $\gamma$-secretase cleavage within the membrane leads to release of the Notch intracellular domain (NICD), which translocates into the nucleus of the signal-receiving cell. NICD then binds co-factors, including CSL, MAML and other co-activators, to induce transcription of target genes in the $H E S$ and $H E Y$ families.

In a subset of cancers, including T cell ALL [13], breast [14], and lung cancer [15], Notch is activated by mutations or translocations that directly alter receptors or other key pathway members (reviewed in: $[16,17]$ ). In most tumors, however, Notch signaling is initiated when receptors on the tumor bind to ligands expressed by adjacent cells. In some tumor microenvironments, Notch ligands are highly expressed on blood vessels $[18,19]$, inflammatory cells [20-22] or other stromal elements [23-25], thus signaling is from non-neoplastic 
cells to cancerous ones. In other contexts, however, tumor cells themselves are known to express both ligands and receptors, and it is thought that signaling between neoplastic cells is a major driver of Notch activity [26, 27].

During normal development, several mechanisms are used to regulate Notch activity when groups of similar cells express both ligand and receptor, with the best studied of these being lateral inhibition. This process, first described in Drosophila, allows the specification of evenly spaced neuroblasts from sheets of undifferentiated epithelial progenitors via feedback loops that reinforce initial differences in ligand and receptor levels between adjacent cells [28, 29]. In the signal-sending cell, generation of a JAG intracellular domain protein [30] is believed to actively repress Notch signaling either by directly binding and sequestering NICDs [31,32] or by binding the Notch transcriptional machinery in the nucleus [33]. While this lateral inhibition paradigm is commonly accepted in developmental biology, to our knowledge it has not been well studied in solid tumors expressing both ligands and receptors on neoplastic cells. We therefore decided to address the possibility that a lateral inhibitionlike process occurs in cancer, using the brain tumor glioblastoma (GBM) as our primary model.

GBM is the most common primary malignant brain tumor. The median survival of patients with this devastating disease is still approximately one year, even after surgical resection, radiation and chemotherapy with temozolomide $[34,35]$. The Notch signaling pathway is increasingly being identified as an important player in the growth and survival of GBM [27, 36, 37], including cancer stem cells in these tumors [38, 39]. This small population of stem-like GBM cells supported by Notch activity appear to be associated with resistance to standard radiation and chemotherapy [38, 40-42].

Notch has been shown to be active in the GBM vascular stem cell niche [39], with signaling driven by Notch ligands present on endothelial cells [19]. However, it has also been demonstrated that Notch activity is upregulated in glioma cells grown in low oxygen culture [43], and in regions of hypoxia in vivo [43-45]. This suggests that at least two alternate microenvironments supporting Notch activity may exist in GBM, a perivascular niche with ligands expressed on vascular elements, and a peri-hypoxic niche with ligands induced on tumor cells. The latter environment, in which both ligands and receptors are expressed on adjacent or intermixed tumor cells, might represent a region in which asymmetry in expression leads to lateral inhibition.

In this study, we examine in greater detail the effects of hypoxia on Notch ligand expression in GBM and pancreatic carcinoma. We also sought to directly model what happens when adjacent tumor cells express differing levels of ligand, identifying a lateral inhibitionlike phenomenon. We also reviewed images from three separate primary GBM specimens from a prior study in which we stained for both Notch ligands and targets [19]. In all three samples, regions of adjacent neoplastic cells expressing either ligand or target were readily identified, supporting the possibility of lateral inhibition in vivo. Finally, we show that ligand ICD is able to mediate effects similar to those seen in lateral inhibition.

\section{RESULTS}

\section{Hypoxia induces expression of the notch ligands JAG1 and JAG2 in GBM neurospheres}

Previous work from our laboratory demonstrated that hypoxia can positively regulate mRNA levels of the Notch ligands JAG1 and JAG2 in GBM neurospheres [43]. We investigated this further in a larger panel of GBM neurosphere lines in which we also assessed the effects of neurosphere growth on ligand levels and pathway activity over several days. Following hypoxia induction in HSRGBM1 neurospheres, we observed the upregulation of JAG1 and JAG2 ligands beginning at 22 hours and 9 hours, respectively (Figure 1A, 1B). We also observed a several-fold increase in mRNA levels of the Notch ligands JAG1 and JAG2 at both 22 and 48 hours post hypoxia induction in the GBM lines JHH-GBM10, JHH-GBM14, 040622 and 040821 (Figure 1C, 1D).

We then extended this analysis to protein, and found levels of ligand induction similar to those seen at the mRNA level. In the HSR-GBM1 line, for example, JAG1 protein was upregulated over 10-fold as shown in Figure 1E. The cleaved (active) from of Notch1 (NICD1) was also induced, suggesting that the increases in ligand level may be driving pathway activity (Figure 1E). The pancreatic cancer cell line XPA3, which is known to be Notch-dependent [46], also showed dramatic upregulation of both JAG1 mRNA and protein in hypoxia (Figure 1F, 1G).

\section{Unequal JAG1 levels in co-cultured cells alters notch signaling in both the signal sending and receiving cells}

To test the effects of increased Notch ligand levels, we generated GBM neurosphere lines that have elevated ligand levels. We induced JAG1 expression in the HSRGBM1 and 040821 neurosphere lines via viral transduction followed by selection with blasticidin antibiotics. These bulk ligand-transduced cultures were found to increase the number of cells expressing JAG1 from approximately $20 \%$ to $80 \%$, as measured by 3 separate immunofluorescent positive cell counts (Figure 2A, Supplemental Figure 1). However, even in the overexpressing cells, JAG1 protein levels varied significantly (Supplemental Figure 1).

This heterogeneous ligand induction resulted in increased levels of Notch pathway activity. The percentage of NICD expressing cells rose approximately 10-fold (Figure 2A, Supplemental Figure 1). Upregulation of 
A

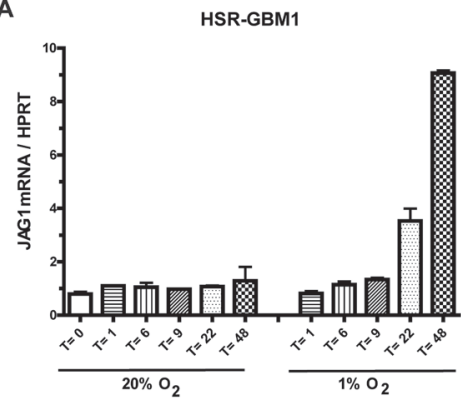

C

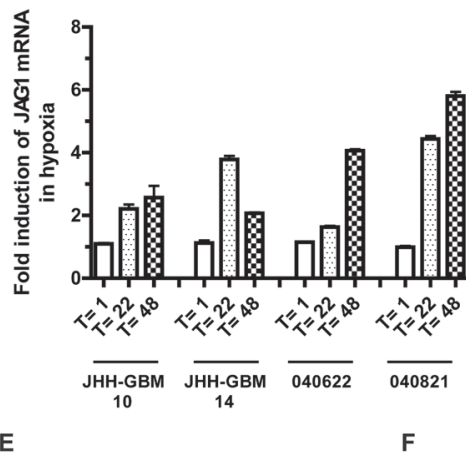

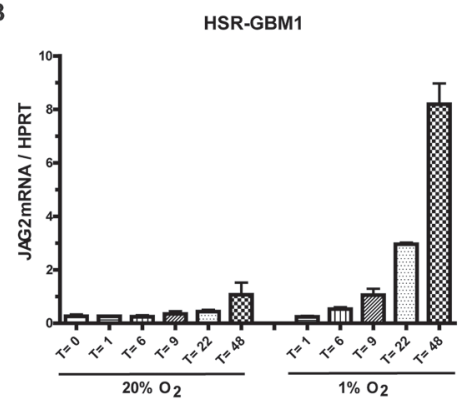

D

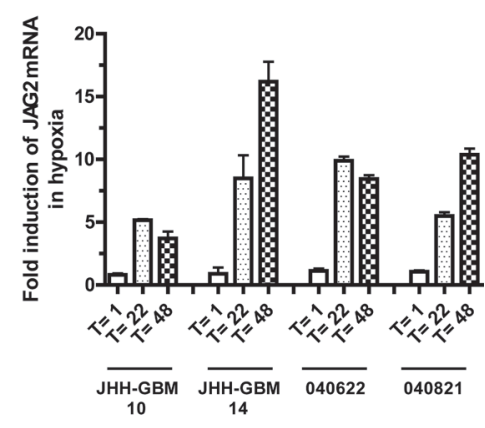

G
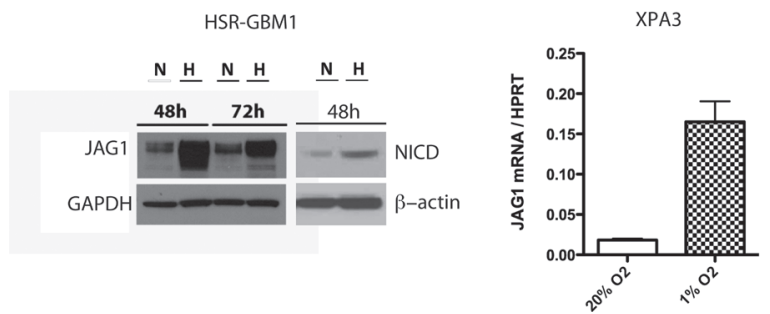

XPA3

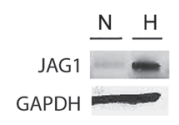

Figure 1: Hypoxia induces Notch ligand expression in malignant tumors. HSR-GBM1 neurospheres were subjected to normoxia $\left(20 \% \mathrm{O}_{2}\right)$ or hypoxia $\left(1 \% \mathrm{O}_{2}\right)$ for $1(T=1), 6(T=6), 9(T=9), 22(T=22)$ and $48(T=48)$ h, at which time they were collected for RNA analyses. (A) JAG1 and (B) JAG2 mRNA levels were both induced soon after hypoxia exposure. (C) JAG1 and (D) JAG2 mRNA levels were similarly upregulated in the GBM neurospheres lines JHH-GBM10, JHH-GBM14, 040621 and 040821. (E) JAG1 and NICD protein levels were also induced following $48 \mathrm{~h}$ exposure to hypoxia, with JAG1 expression enduring at $72 \mathrm{~h}$. The pancreatic cancer cell line XPA3 also induces JAG1 (F) mRNA and (G) protein levels following $48 \mathrm{~h}$ exposure to hypoxia.

the HES1, HES5 and HEY1 targets was also noted in both HSR-GBM1 (Figure 2B) and 040821 (Figure 2C) GBM neurospheres, but was generally less dramatic than the change in the percentage of NICD expressing cells. Overexpression of JAG1 also induced HES1, but not HEY1, in the pancreatic cancer cell line XPA3 (Figure 2D).

To more directly model how unequal JAG1 levels in the hypoxic microenvironment, or other areas where they are not uniformly expressed, might affect Notch activity, we engineered a system in which JAG1 was elevated in a more controlled subset of cells. To achieve this, cells overexpressing JAG1 and vector transduced controls with lower levels of the ligand were co-cultured. These two populations were then sorted using flow cytometry and levels of pathway targets were measured by quantitative PCR (Figure 3A). The effects of co-culture on Notch activity were dramatically different in these two populations. Vector transduced (JAG1-low) cells in the two GBM cultures examined showed a significant induction of pathway targets when brought in contact with JAG1-high cells of the same line (light and dark green bars in Figure 3B, 3C). In contrast, the high baseline levels of Notch activity in cultures transduced with JAG1 were dramatically suppressed after co-culture with sister cells differing only in their lower ligand expression (white and grey bars in Figure 3B, 3C). We also observed similar effects on HES1 transcript levels following co-culture of JAG1-high and -low XPA3 pancreatic cancer cells (Figure 3D). Sorting either JAG1 high or low GBM1 cells without co-culture resulted in a modest elevation of HES5 expression, suggesting that the pathway inhibition on co-culture was not a side effect of flow cytometric manipulation (data not shown). These observations suggest that lateral inhibition, a mechanism specifying cell fate during development by downregulating pathway activity in ligand-high "signal sending" cells, can also occur in tumors. 

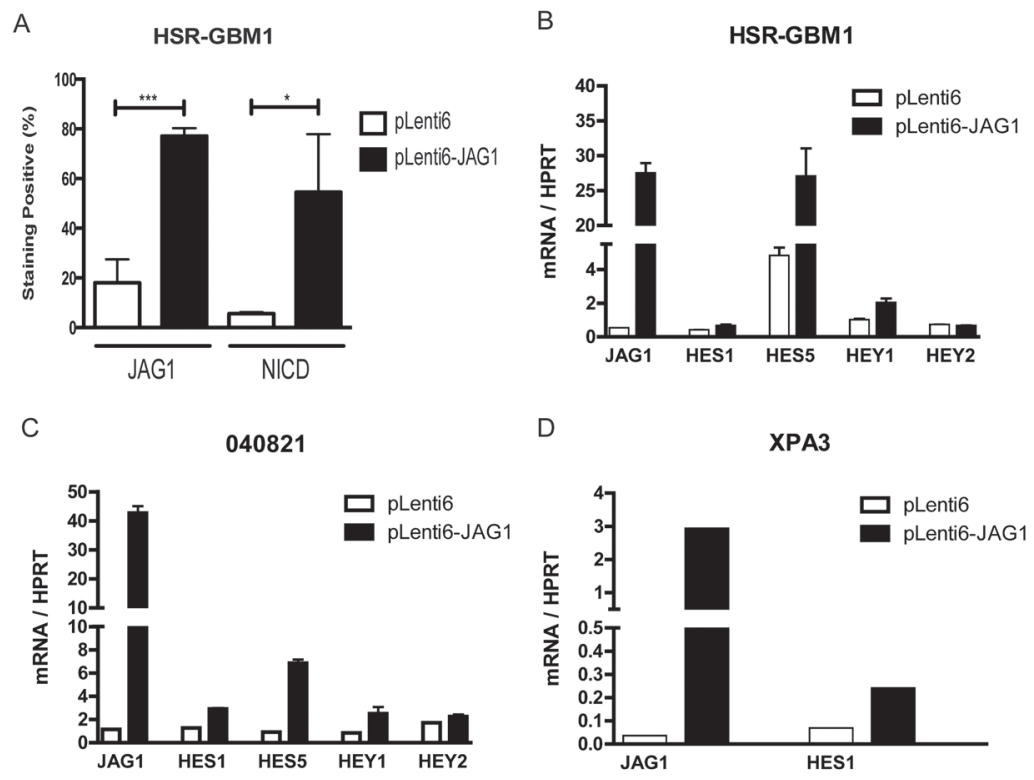

Figure 2: Ectopic ligand expression induces Notch signaling. (A) Lentiviral transduction of $J A G 1$ resulted in $80 \%$ of cells expressing ligand compared to $20 \%$ in the control based on three separate immunofluorescence studies (Supplemental Figure 1). The percentage of cells expressing NICD was upregulated approximately 10-fold. Overexpression of JAG1 ligands in (B) HSR-GBM1, (C) 040821 and (D) XPA3 lines upregulates Notch targets from the HES and HEY families. ${ }^{*} p<0.01$, $* * * p<0.001$ compared to pLenti6 control from 3 experiments.

\section{The JAG1 intracellular domain reduces notch signaling and decreases clonogenic growth in GBM neurospheres}

We next investigated the mechanism causing downregulation of Notch target gene levels in JAG1high GBM cells following co-culture with paired JAG1low cells. Like the Notch receptor, JAG ligands are also subjected to $\alpha$-secretase and $\gamma$-secretase cleavage, which leads to the production of intracellular domain (ICD) proteins able to translocate into the nucleus and affect pathway activity [30, 33, 47-49]. We investigated ligand ICD levels in GBM neurospheres after hypoxia exposure or JAG1 overexpression. A low molecular weight band of a size consistent with ligand ICD appeared in hypoxia (Figure 4). It was absent under standard normoxic conditions, but was detectable in the presence of the proteasome inhibitor lactacystin. Similarly, overexpression of Jagged1 in GBM neurospheres led to an increase in ICD production (Figure 4). These results suggest that the cleaved ligand ICD may modulate Notch activity in GBM neurospheres.

We therefore investigated the effects of overexpression of ligand ICD in our GBM cells. We first generated human JAG1 ligand ICD constructs and cloned them into viral vectors. GBM neurospheres were transduced with viruses containing the control vector pLenti6 or pLenti6-JAG1ICD and were subsequently selected with blasticidin antibiotics. We observed a modest but significant reduction in HES and HEY transcripts in ligand ICD overexpressing HSR-GBM1 and 040821 cells (Figure 5A, 5B), consistent with the concept that cleavage and release of the ligand ICD in the "signal sending" cell can suppress Notch pathway activity.

We have previously shown that the size of anchorage-independent colonies correlates with either their derivation from GBM cancer stem cells or more restricted progenitors, as colonies over $100 \mu \mathrm{M}$ in size can be serially passaged, while those less than $50 \mu \mathrm{M}$ cannot [43]. Thus, we next investigated the ability of GBM cells to form colonies over several weeks following ligand ICD overexpression. Approximately 20,000 HSR-GBM1 cells were seeded in methylcellulose and grown for 10-13 days. Subsequent sphere formation was monitored and scored by light microscopy. The mean diameter of cells infected with the control vector pLenti6 was $131 \mu \mathrm{M}$ while cells infected with JAG1ICD were $93 \mu \mathrm{M}$ (Figure 5C). There was a significant difference $(p<0.001)$ in the size of pLenti6 and pLenti6-JAG1ICD spheres, consistent with the concept that ligand ICD expression can suppress clonogenic capacity.

To further investigate the mechanism by which ligand ICD inhibits Notch signaling and reduces growth and clonogenicity in GBM cells, we examined its subcellular localization. After transducing HSR-GBM1 cells with pLVU/RED (C-terminal DsRed-tagged) JAG1ICD, fluorescent microscopy analysis showed that JAG1ICD localizes predominantly in the nucleus (Figure 5D), suggesting that like the Notch receptor ICD, ligand ICD may act in the nucleus to modulate 
HSR-GBM1

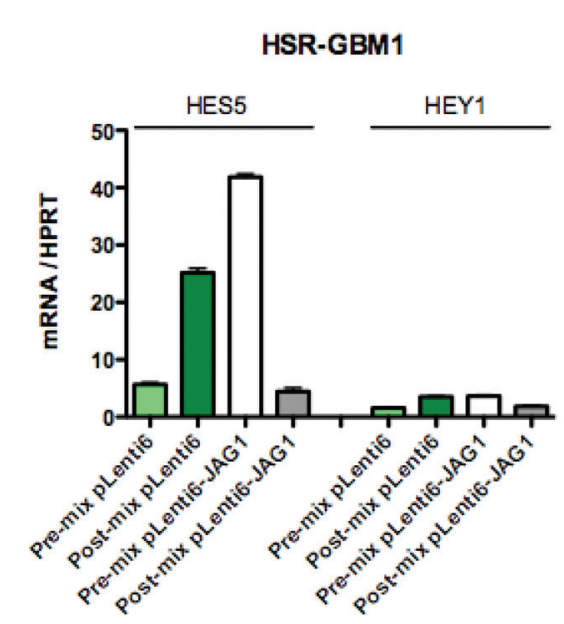

040821

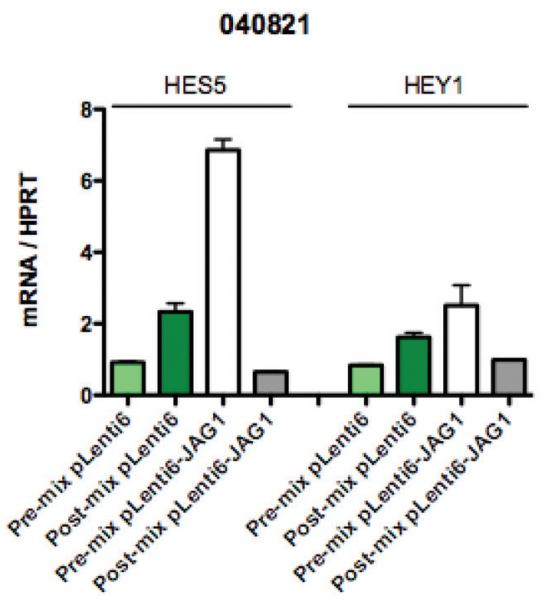

D

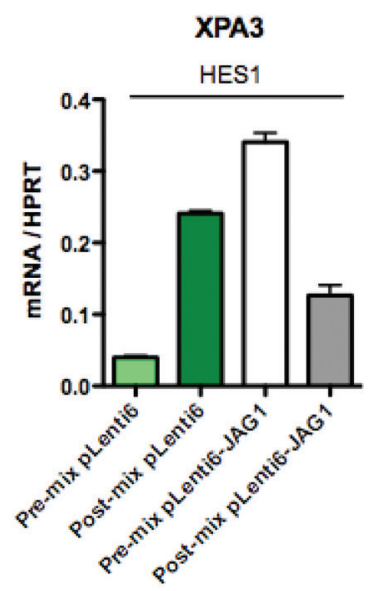

Figure 3: JAG-low cells are primed to respond to Notch receptor signals. (A) In the co-culture experiments, GBM pLenti6 control cells were stained with CFSE and mixed with isogenic cells overexpressing JAG1 ligands (no CFSE stain) and co-cultured. After co-culture for $17 \mathrm{~h}$, cells were sorted into their respective initial populations using the CFSE staining and analyzed by qPCR. (B) HES5 and HEY1 transcripts were upregulated following co-culture in pLenti6 (B) HSR-GBM1 and (C) 040821 cells while the same transcripts were downregulated in pLenti6-JAG1 cells. Similarly, following co-culture, HES1 transcripts were upregulated in (D) XPA3 pLenti6 cells but downregulated in pLenti6-JAG1 cells. ${ }^{* *} p<0.01,{ }^{* * *} p<0.001$ compared to pre-mix control.

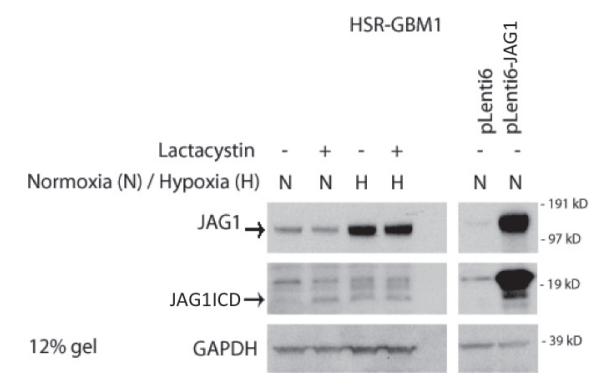

Figure 4: Hypoxia and JAG1 overexpression increases ligand ICD production. Hypoxia induces full length JAG1 production and increases ICD ( 16 kD) stability. Similarly, overexpression of JAG1 increases the expression of the ligand ICD band.

transcription. This may explain why the induction of NICD we observed in Figure 2 was more prominent than that of transcriptional targets of the pathway.

\section{DISCUSSION}

To most effectively target Notch in cancer, it will be necessary to understand in which subsets of cells it is active and how this activation is achieved. Notch ligands have been found to be upregulated in many types of cancer, and such ligands expressed on tumor cells themselves may provide the driving force behind pathway induction in some contexts. We therefore investigated the role of Notch ligands in GBM and pancreatic carcinoma, focusing on their induction in a hypoxic tumor microenvironment and the possibility that heterogeneous ligand levels might have complex effects on pathway induction analogous to those seen in normal development.

A recent study of JAG1 expression by immunohistochemistry in pseudopalisading GBM tumor 

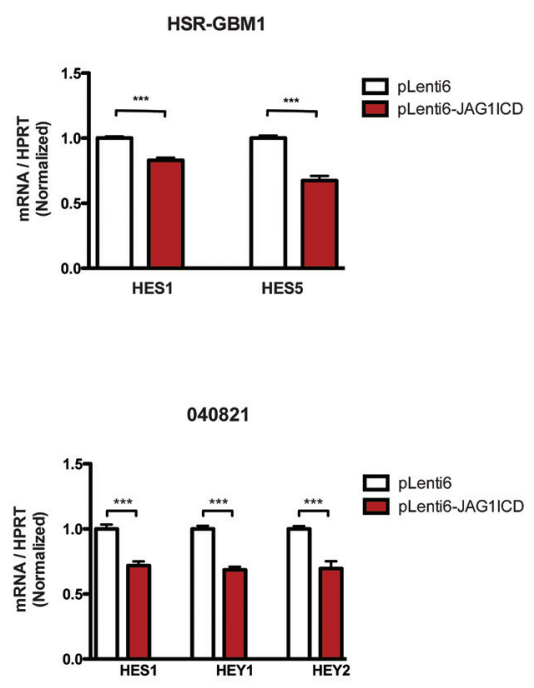

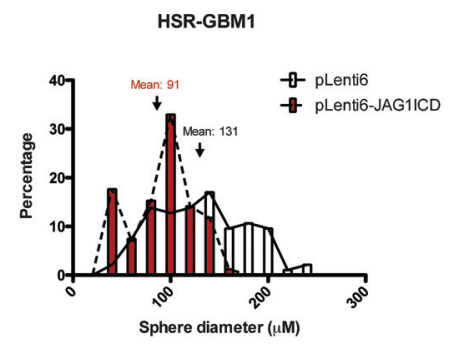

D

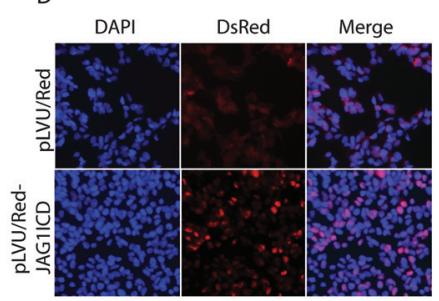

Figure 5: JAG1 ligand ICD reduces Notch signaling, potentially through nuclear localization. Notch target levels were reduced in (A) HSR-GBM1 and (B) 040821 cells transduced with ligand ICD. The average sphere diameter of (C) HSR-GBM1 cells transduced with ligand ICDs was reduced in a clonogenic assay. (D) HSR-GBM1 cells transduced with C-terminus DsRed tagged JAG1ICD showed distinct nuclear localization, in distinct contrast to the pLVU/Red vector control transduced cells.

cells suggests that hypoxia can focally promote its expression in tumor cells surrounding necrotic regions, resulting in unequal ligand levels [44]. We confirmed the dramatic induction of Notch ligand mRNA and protein in GBM and pancreatic carcinoma cultures when placed in hypoxic conditions (Figure 1). However, our data also suggest that unequal JAG1 ligand levels in a mixed tumor cell population results in dramatically different effects on the heterogeneous cells.

In many ligand-receptor pairs, increased ligand expression leads to increased signaling in the receiving cell, but no decrement in the sending cell. For the Notch pathway, lateral inhibition occurs when differential expression of ligands in adjacent cells leads not only to induction of Notch signaling in the ligand-low cell, but also to pathway inhibition in the ligand-high cell (Figure 6A). In normal development, this results in the specification of distinct cell types from an undifferentiated field [50].

Our study suggests that an analogous process can occur in malignant cells. Two tumor systems were examined: GBM neurospheres and an adherent pancreatic carcinoma line. In both tumor types, introduction of JAG1 into the cancer cells increased overall Notch signaling levels in the culture, but we still observed heterogeneity in ligand levels, which likely facilitated this overall pathway induction and made it difficult to separate signal sending and receiving cells. However, when ligand high cells were co-cultured with the ligand low matched controls, the changes in Notch signaling recapitulated those seen in classical lateral inhibition. Following co-culture and sorting, pathway targets were increased in ligand low (signal-receiving) cells, while the same targets were greatly reduced from baseline in high JAG1 (signalsending) cells.

A number of prior reports have indicated that Notch receptors, ligands and/or targets are heterogeneously expressed in primary glioma $[27,44,51-53]$ and pancreatic carcinoma [54-56] specimens, suggesting that a lateral inhibition like phenomenon could occur in patients. We investigated if the mutually exclusive expression of a Notch pathway ligand (JAG1) and target (HES5) consistent with lateral inhibition could be found in primary glioblastoma by examining in greater detail three previously reported, double stained GBM specimens [19]. In all three cases examined, while the relative proportions of ligand and target expressing cells varied significantly, they were in general roughly equivalent in number, with a much smaller population of cells that appeared to express both ligand and target. Tightly stereotyped patterns of expression similar to those described in developing Drosophila epithelium were not observed. However, we estimate that $40-60 \%$ of the overall tumor areas examined showed a largely mutually exclusive pattern of expression in neoplastic-appearing cells, as illustrated in Figure 6B. While larger numbers of cases and additional ligands and targets will need to be examined to determine the full prevalence and impact of lateral inhibition in tumors of the brain and other tissues, our preliminary studies support the general notion that such a process can occur in vitro and in vivo.

To explore the mechanism by which Notch signaling is reduced in JAG1-high cells, we looked at protein expression under hypoxia and in the context of ligand overexpression. Both conditions resulted in increased JAG1 ICD protein predominantly localized to the nucleus of the 


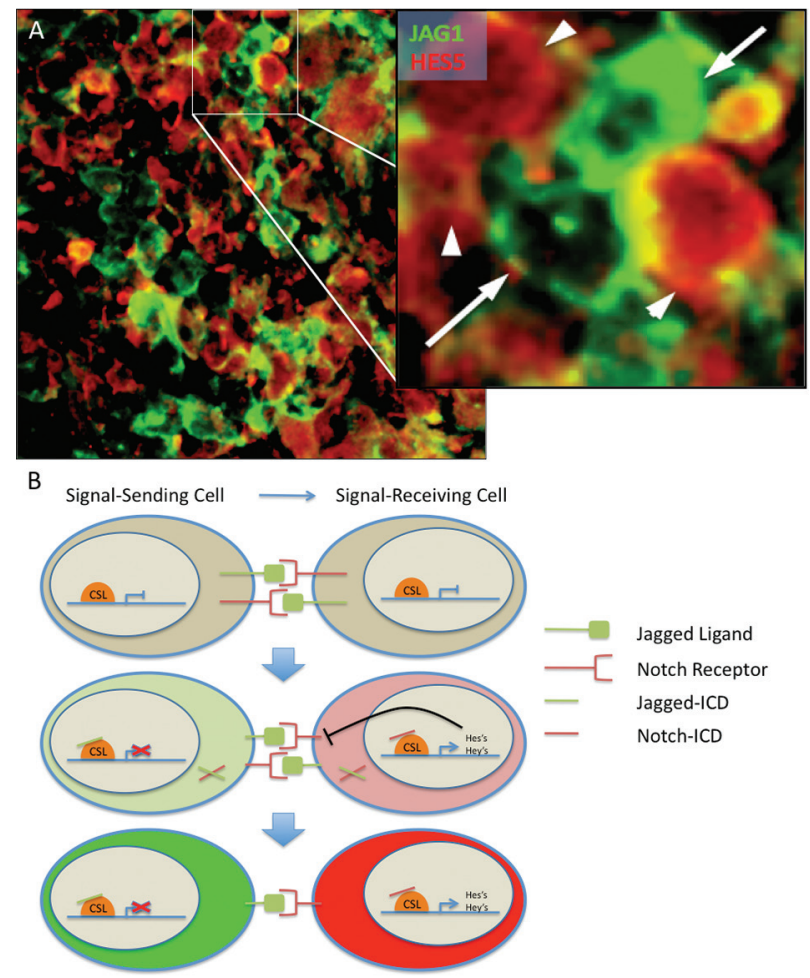

Figure 6: Modeling Notch signaling in GBM. (A) Notch regulates differentiation through lateral inhibition, whereby activation of the pathway results in the production of a ligand ICD as well as a receptor ICD. The ligand ICD inhibits NICD-driven transcription in the signal-sending cell whereas NICD induces transcription in the signal-receiving cell. (B) Expression of JAG1 and HES5 are generally mutually exclusive. Notch ligand JAG1-expressing cells (green, arrow) are adjacent to, but mostly mutually exclusive from, Notch target HES5-expressing cells (red, arrowhead) in a primary GBM tumor sample. Similar results were seen in the two additional cases analyzed.

cell. Overexpression of ligand ICD was found to reduce Notch target expression as well as clonogenicity of GBM neurospheres. Recent studies have demonstrated nuclear localization of Notch ligands in Drosophila [47], mouse [30] and rat [33]. In addition, potential nuclear localization signals (NLS) have previously been identified in human DLL1 [57]. It is therefore possible that the attenuation of Notch activity could be linked to the nuclear localization of ligand ICDs. Our results also support previous reports by Jung et al and Kim et al, which suggested that the ligand ICD can attenuate Notch signaling via translocation into the nucleus and binding to NICD [31,32].

To our knowledge, this is the first specific investigation of lateral inhibition occurring in tumor cells. A recent study on adrenocortical carcinoma used a similar co-culture strategy to demonstrate that JAG1 functions in a non-cell-autonomous manner to induce signaling, and is at least partially responsible for aggressive cellular proliferation [58]; however, pathway suppression in the ligand high cells was not examined. Understanding the heterogeneity of Notch activity in tumors, how they relate to microenvironmental factors such as hypoxia, and the sources of ligand that drive the pathway may allow us to more rationally target Notch in cancer. The finding that JAG1 ligand ICD can suppress pathway activity and tumor growth also represents a new possible therapeutic strategy.

\section{MATERIALS AND METHODS}

\section{Immunofluorescence}

Primary GBM tumor samples were fixed in $4 \%$ paraformaldehyde overnight at $4{ }^{\circ} \mathrm{C}$, cryoprotected with $30 \%$ sucrose saturation, and cryoembedded in Tissue-Tek OCT. Tissue sections $(8 \mu \mathrm{m}$ thick) were permeabilized with $0.4 \%$ Triton-X-100 for $25 \mathrm{~min}$ at room temperature and blocked with 5\% BSA in PBS for $20 \mathrm{~min}$ at room temperature. Samples were incubated with primary antibodies overnight at $4{ }^{\circ} \mathrm{C}$ and secondary antibodies were applied for $1 \mathrm{~h}$ at room temperature. Primary antibodies and dilutions used for immunofluorescence were JAG1 (Cell Signaling, 2155, 1:100), HES5 (Santa Cruz, sc-13859, 1:50), and cleaved-NOTCH1 (Cell Signaling, $4147,1: 100)$. Secondary antibodies used were Cy2 or Cy3 conjugated antibody (1:500, Jackson Immuno Research). For cleaved-NOTCH1 immunofluorescence, and the JAG1 immunofluorescence in Figure 2A and Supplemental Figure 1, a Powervision poly-HRP-anti-rabbit secondary (Dako) was used, followed by Cy3 TSA amplification (Perkin-Elmer, NEL704 A, 1:50). Immunofluorescence slides were counterstained with DAPI, mounted with anti-fade Prolong Gold (Invitrogen) and imaged using an Olympus BX-51 fluorescence microscope. 


\section{Cell lines and cultures}

The GBM neurosphere lines HSR-GBM1, 040622 and 040821 were kind gifts from Dr. Angelo Vescovi and were propagated in serum-free media as previously described [59]. JHH-GBM10 and JHH-GBM14 neurosphere lines originated from tumors resected at Johns Hopkins University and were propagated in the same manner [60]. The pancreatic cancer line XPA3, a kind gift from Dr. Anirban Maitra (JHU), was propagated in RPMI with $10 \%$ FBS.

\section{Hypoxia time course analyses}

HSR-GBM1, JHH-GBM10, JHH-GBM14, 040622 and 040821 neurosphere lines were plated at a density of 100,000 cells / $\mathrm{ml}$ media overnight, then exposed to $1 \%$ oxygen (hypoxia). Cells were harvested at 1, 6, 9, 22 and $48 \mathrm{~h}$ following hypoxic induction. Control cells were exposed to $20 \%$ oxygen (normoxia) and collected at the same time points. Approximately $4 \times 10^{6}$ XPA3 cells were plated in 10-cm dishes, allowed to attach overnight, and exposed to hypoxia or normoxia for $48 \mathrm{~h}$.

\section{Co-culture analyses}

HSR-GBM1 and 040821 cells were transduced with lentiviruses encoding control pLenti6 vectors or JAG1 constructs. At least $5 \times 10^{5}$ cells in each line (premix cells) were collected per line for RNA extraction. $5 \times$ $10^{6}$ control vector cells were stained with the viable dye Carboxyfluorescein Diacetate Succinimidyl Ester (CFSE) according to manufacturer's instructions (Invitrogen,
Carlsbad, CA) and co-cultured with the same number of JAG1 overexpressing cells in a T75 flask for $17 \mathrm{~h}$. Co-cultured cells were then sorted into CFSE-positive (pLenti6) or CFSE-negative (plenti6-JAG1) populations by flow cytometry. Similarly, $6 \times 10^{6}$ control vector and $6 \times 10^{6} \mathrm{JAG} 1$ XPA 3 cells were co-cultured in a T75 flask for $17 \mathrm{~h}$ prior to sorting. The experiment was performed at least twice in each cell line.

\section{RNA analyses}

RNA was extracted with Qiagen's RNeasy kit (Valencia, CA). RNA levels were assayed by real-time PCR analysis performed in triplicate with SYBR Green reagent (Applied Biosystems, Foster City, CA) according to the manufacturer's instructions on an I-Cycler IQ real-time detection system (Bio-Rad, Hercules, CA), with all reactions normalized to HPRT. To minimize contaminating genomic DNA, a 15-minute on-column DNase step (Qiagen RNase-free DNase kit) was included during RNA extraction. To measure the reaction efficiency, standard curves were generated for each primer pair using the standards of $0.05,0.5,5$ and $50 \mathrm{ng}$ of total starting RNA from HSR-GBM1 cells. In addition, all primer sets were verified by melting curves that demonstrated the amplification of a single product. Primer sequences are shown in Table 1.

\section{Protein analyses}

Cells were first resuspended in TNE buffer containing $50 \mathrm{mM}$ Tris, $150 \mathrm{mM} \mathrm{NaCl}, 5 \mathrm{mM}$ EDTA, $1 \mathrm{mM}$ PMSF, $10 \mathrm{mM} \mathrm{NaF}, 2 \mathrm{mM} \mathrm{Na}_{3} \mathrm{VO}_{4}$ and complete

Table 1: Primer sequences used for qPCR analyses

\begin{tabular}{|c|c|}
\hline Primer Name & Sequence \\
\hline HPRT Forward & 5'- CTT TGC TGA CCT GCT GGA TT -3' \\
\hline HPRT Reverse & 5'- GTT GAG AGA TCA TCT CCA CC -3' \\
\hline HES1 Forward & 5'- GTG AAG CAC CTC CGG AAC -3' \\
\hline HES1 Reverse & 5'- CGT TCA TGC ACT CGC TGA -3' \\
\hline HES5 Forward & 5'- GTG CCT CCA CTA TGA TCC TTA AA -3' \\
\hline HES5 Reverse & 5'- AGT ACA AAG TCG TGC CCA CA -3' \\
\hline HEY1 Forward & 5'- TCT GAG CTG AGA AGG CTG GT -3' \\
\hline HEY1 Reverse & 5'- CGA AAT CCC AAA CTC CGA TA -3 \\
\hline HEY2 Forward & 5'- AGA TGC TTC AGG CAA CAG GG -3' \\
\hline HEY2 Reverse & 5'- CAA GAG CGT GTG CGT CAA AG -3' \\
\hline JAG1 Forward & 5'- GAA TGG CAA CAA AAC TTG CAT -3 \\
\hline JAG1 Reverse & 5'- AGC CTT GTC GGC AAA TAG C -3' \\
\hline JAG2 Forward & 5'- TGG GAC TGG GAC AAC GAT AC - $3^{\prime}$ \\
\hline JAG2 Reverse & 5'- ATG CGA CAC TCG CTC GAT -3' \\
\hline
\end{tabular}


protease inhibitors (Roche). Resuspended cells were then lysed in an equal volume of TNE buffer containing detergents (1\% NP-40, 1\% deoxycholate, 2\% SDS), and then sonicated for 20 seconds at 5-second intervals, and cooled on ice between intervals. Western blots containing at least $20 \mu \mathrm{g}$ total protein per lane on a NuPAGE 4-12\% BisTris gel (NP0321BOX) were electrophoresed in 1x NuPAGE MOPS SDS running buffer in an XCell SureLock mini gel apparatus (all from Invitrogen). Proteins were then transferred to Biorad's Immun-blot PVDF membrane in 1x NuPAGE transfer buffer in an $\mathrm{X}$ Cell II Blot module (Invitrogen). Membranes were blocked for $1 \mathrm{~h}$ at room temperature in 5\% non-fat milk and incubated at $4{ }^{\circ} \mathrm{C}$ overnight in primary antibodies containing 5\% non-fat milk. JAG1 antibody (H114, sc-8303) was purchased from Santa Cruz Biotechnology and used at a 1:1000 concentration in blocking solution. V5 mouse monoclonal antibodies were purchased from Sigma. Mouse anti-rabbit GAPDH antibodies were purchased from Research Diagnostics (RDI-TRK5G46C5). Cleaved-NOTCH1 was purchased from Cell Signaling (4147) and used at a 1:800 concentration. $\beta$-actin was purchased from Santa Cruz Biotechnology and used at a 1:20,000 concentration in blocking solution. Secondary antibodies from KPL (peroxidase-conjugated goat antimouse [074-1806] or rabbit IgG [074-1506]) were diluted 1:5,000 in blocking solution. Blots were developed with enhanced chemiluminescence reagent (NEL103001EA, PerkinElmer).

\section{Plasmids and expression constructs}

Constructs used for co-culture analyses and subsequent functional assays were cloned into the Gateway $^{\circledR}$ pLenti6 plasmid containing a V5 epitope at the carboxy terminus. Full length human JAG1 (M1 to V1218) in pLenti6 was constructed by transferring the JAG1 gene from pENTR-JAG1 (Addgene) into the pLenti6 destination vector via an LR reaction according to manufacturer's instructions (Invitrogen). JAGIICD (R1094 to V1218) was cloned into Gateway ${ }^{\circledR}$ entry vector via BP cloning. First, attB PCR products were generated using the primers in Table 2. PCR products were recombined into the Gateway ${ }^{\circledR}$ entry vector pDONR-221 in a BP reaction according to manufacturer's directions and then transferred to the pLenti6 destination vector via an LR reaction. Constructs were transformed into chemically competent Stbl3 bacteria for plasmid DNA amplification. Protein expression was verified by western blotting using anti-V5 antibodies. pLVU/RED [61] constructs were obtained by transferring the gene from a Gateway ${ }^{\circledR}$ entry/donor vector into the pLVU/RED destination vector via an LR reaction.

\section{Lentivirus preparation and infection}

Lentiviruses (from pLenti6, pLVU vectors) were produced in HEK 293T cells, followed by purification and concentration. Briefly, 4 plasmids $(20 \mu \mathrm{g}$ transfer vector with expression construct, $10 \mu \mathrm{g}$ of packaging construct pMDL-g/pRRE, $5 \mu \mathrm{g}$ pRSV-REV, $5 \mu \mathrm{g}$ pMD2-VSVG) were used to co-transfect using $60 \mu \mathrm{l}$ lipofectamine in $1.5 \mathrm{ml}$ serum-free media, according to manufacturer's instructions in an $80 \%$ confluent T-75 flask. The next morning, the transfection media was replaced with fresh media containing 2\% FBS in DMEM. Viruses were harvested at $48 \mathrm{~h}$ and $72 \mathrm{~h}$ and concentrated by PEG precipitation. Briefly, the viral supernatant was passed through a $0.45 \mu \mathrm{M}$ low protein-binding filter. $50 \%$ PEG 8000 was added to the viral supernatant to a final concentration of $5 \%$, and then $1.5 \mathrm{M} \mathrm{NaCl}$ was added to the virus-PEG mixture to a final concentration of $0.15 \mathrm{M}$ and incubated overnight at $4^{\circ} \mathrm{C}$. The precipitate was then centrifuged at $2000 \mathrm{~g}$ at $4^{\circ} \mathrm{C}$ for $30 \mathrm{~min}$. Approximately 250,000 neurospheres were infected with concentrated virus overnight and changed to fresh media the next morning. After 3 days, transduced cells were selected with 2.5-5 $\mu \mathrm{g} / \mathrm{ml}$ blasticidin antibiotics (pLenti6 constructs).

\section{Clonogenic assay}

Clonogenic assays were performed in 6-well plates that were pre-coated with $500 \mu \mathrm{l}$ of $12 \mathrm{mg} / \mathrm{ml}$ poly (2-hydroxyethyl methacrylate) (Sigma, St. Louis, MO) in $95 \%$ ethanol. The plates were allowed to dry at $37^{\circ} \mathrm{C}$. Wells were first overlaid with $2 \mathrm{ml}$ of $1.5 \%$ methyl cellulose (Fisher, M-352, Pittsburgh, PA) in NSA (MCNSA), and then incubated for $1 \mathrm{~h}$ at $37^{\circ} \mathrm{C}$ before plating. For each well, cells were resuspended with $1.5 \%$ MCNSA at a 1:3 ratio in a total volume of $2 \mathrm{ml}$. Cells were fed $0.5 \mathrm{ml}$ of $1.5 \%$ MCNSA every 2 to 3 days. Subsequent sphere formation was monitored and scored by light microscopy after 10 to 13 days. Five random fields at $4 \mathrm{x}$ magnification were photographed in triplicate for each

Table 2: Gateway primers used for designing attB PCR gene products. Underlined sequence $(\underline{\mathrm{ATG}})$ denotes start codon.

\begin{tabular}{|c|c|c|}
\hline Primer & attB1/B2 sequences & Gene specific sequences \\
\hline $\begin{array}{l}\text { JAG1ICD_} \\
\text { GTW_Forward }\end{array}$ & $\begin{array}{l}\text { GGGGACAAGTTTGTACAAAAAAGCAGGCTTCGA } \\
\text { AGGAGATAGAACCATGGCG }\end{array}$ & CGGAAGCGGCGGAAGCCGGGCAGCC \\
\hline $\begin{array}{l}\text { JAG1ICD_- } \\
\text { GTW Reverse }\end{array}$ & GGGGACCACTTTGTACAAGAAAGCTGGGTC & TACGATGTACTCCATTCGGTTTAAGC \\
\hline
\end{tabular}


condition and all measurements were performed using a Motic AE31 light microscope equipped with a Moticam 2300 camera and analyzed using the Motic Images Plus 2.0 ML software (Motic Instruments, Richmond BC, Canada) as previously described [43].

\section{Editorial note}

This paper has been accepted based in part on peerreview conducted by another journal and the authors' response and revisions as well as expedited peer-review in Oncotarget.

\section{ACKNOWLEDGEMENTS}

This work was supported by NIH grants: RO1NS055089 (CGE), R01CA148621 and R01CA163737 (XF).

\section{Conflict of interest}

The authors have no known conflicts of interest.

\section{REFERENCES}

1. Ellisen LW, Bird J, West DC, Soreng AL, Reynolds TC, Smith SD, Sklar J. TAN-1, the human homolog of the Drosophila notch gene, is broken by chromosomal translocations in T lymphoblastic neoplasms. Cell. 1991; 66:649-661.

2. Pancewicz J, Nicot C. Current views on the role of Notch signaling and the pathogenesis of human leukemia. BMC cancer. 2011; 11:502.

3. Balint K, Xiao M, Pinnix CC, Soma A, Veres I, Juhasz I, Brown EJ, Capobianco AJ, Herlyn M, Liu ZJ. Activation of Notch1 signaling is required for beta-catenin-mediated human primary melanoma progression. The Journal of clinical investigation. 2005; 115:3166-3176.

4. Brennan K, Brown AM. Is there a role for Notch signalling in human breast cancer?. Breast cancer research : BCR. 2003; 5:69-75.

5. Dievart A, Beaulieu N, Jolicoeur P. Involvement of Notch1 in the development of mouse mammary tumors. Oncogene. 1999; 18:5973-5981.

6. Hopfer O, Zwahlen D, Fey MF, Aebi S. The Notch pathway in ovarian carcinomas and adenomas. British journal of cancer. 2005; 93:709-718.

7. Dang TP, Gazdar AF, Virmani AK, Sepetavec T, Hande KR, Minna JD, Roberts JR, Carbone DP. Chromosome 19 translocation, overexpression of Notch3, and human lung cancer. Journal of the National Cancer Institute. 2000; 92:1355-1357.

8. Santagata S, Demichelis F, Riva A, Varambally S, Hofer MD, Kutok JL, Kim R, Tang J, Montie JE, Chinnaiyan AM,
Rubin MA, Aster JC. JAGGED1 expression is associated with prostate cancer metastasis and recurrence. Cancer Res. 2004; 64:6854-6857.

9. Miyamoto Y, Maitra A, Ghosh B, Zechner U, Argani P, Iacobuzio-Donahue CA, Sriuranpong V, Iso T, Meszoely IM, Wolfe MS, Hruban RH, Ball DW, Schmid RM, Leach SD. Notch mediates TGF alpha-induced changes in epithelial differentiation during pancreatic tumorigenesis. Cancer Cell. 2003; 3:565-576.

10. Espinoza I, Pochampally R, Xing F, Watabe K, Miele L. Notch signaling: targeting cancer stem cells and epithelialto-mesenchymal transition. OncoTargets and therapy. 2013; 6:1249-1259.

11. Pannuti A, Foreman K, Rizzo P, Osipo C, Golde T, Osborne B, Miele L. Targeting Notch to target cancer stem cells. Clin Cancer Res. 2010; 16:3141-3152.

12. Reya T, Morrison SJ, Clarke MF, Weissman IL. Stem cells, cancer, and cancer stem cells. Nature. 2001; 414:105-111.

13. Zhu YM, Zhao WL, Fu JF, Shi JY, Pan Q, Hu J, Gao XD, Chen B, Li JM, Xiong SM, Gu LJ, Tang JY, Liang H, Jiang H, Xue YQ, Shen ZX, et al. NOTCH1 mutations in T-cell acute lymphoblastic leukemia: prognostic significance and implication in multifactorial leukemogenesis. Clin Cancer Res. 2006; 12:3043-3049.

14. Reedijk M, Odorcic S, Chang L, Zhang H, Miller N, McCready DR, Lockwood G, Egan SE. High-level coexpression of JAG1 and NOTCH1 is observed in human breast cancer and is associated with poor overall survival. Cancer Res. 2005; 65:8530-8537.

15. Westhoff B, Colaluca IN, D'Ario G, Donzelli M, Tosoni D, Volorio S, Pelosi G, Spaggiari L, Mazzarol G, Viale G, Pece S, Di Fiore PP. Alterations of the Notch pathway in lung cancer. Proc Natl Acad Sci U S A. 2009; 106:22293-22298.

16. Ranganathan P, Weaver KL, Capobianco AJ. Notch signalling in solid tumours: a little bit of everything but not all the time. Nat Rev Cancer. 2011; 11:338-351.

17. Roy M, Pear WS, Aster JC. The multifaceted role of Notch in cancer. Curr Opin Genet Dev. 2007; 17:52-59.

18. Steg AD, Katre AA, Goodman B, Han HD, Nick AM, Stone RL, Coleman RL, Alvarez RD, Lopez-Berestein G, Sood AK, Landen CN. Targeting the notch ligand JAGGED1 in both tumor cells and stroma in ovarian cancer. Clin Cancer Res. 2011; 17:5674-5685.

19. Zhu TS, Costello MA, Talsma CE, Flack CG, Crowley JG, Hamm LL, He X, Hervey-Jumper SL, Heth JA, Muraszko KM, DiMeco F, Vescovi AL, Fan X. Endothelial cells create a stem cell niche in glioblastoma by providing $\mathrm{NOTCH}$ ligands that nurture self-renewal of cancer stem-like cells. Cancer research. 2011; 71:6061-6072.

20. Outtz HH, Wu JK, Wang X, Kitajewski J. Notch1 deficiency results in decreased inflammation during wound healing and regulates vascular endothelial growth factor receptor-1 and inflammatory cytokine expression in macrophages. Journal of immunology. 2010; 185:4363-4373. 
21. Palaga T, Buranaruk C, Rengpipat S, Fauq AH, Golde TE, Kaufmann SH, Osborne BA. Notch signaling is activated by TLR stimulation and regulates macrophage functions. European journal of immunology. 2008; 38:174-183.

22. Wang YC, He F, Feng F, Liu XW, Dong GY, Qin HY, $\mathrm{Hu} \mathrm{XB}$, Zheng MH, Liang L, Feng L, Liang YM, Han H. Notch signaling determines the M1 versus M2 polarization of macrophages in antitumor immune responses. Cancer Res. 2010; 70:4840-4849.

23. Jones RK, Searle RF, Stewart JA, Turner S, Bulmer JN. Apoptosis, bcl-2 expression, and proliferative activity in human endometrial stroma and endometrial granulated lymphocytes. Biology of reproduction. 1998; 58:995-1002.

24. Shao H, Cai L, Grichnik JM, Livingstone AS, Velazquez OC, Liu ZJ. Activation of Notch1 signaling in stromal fibroblasts inhibits melanoma growth by upregulating WISP-1. Oncogene. 2011; 30:4316-4326.

25. Zhang J, Wang Y, Li D, Jing S. Notch and TGF-beta/Smad3 pathways are involved in the interaction between cancer cells and cancer-associated fibroblasts in papillary thyroid carcinoma. Tumour biology: the journal of the International Society for Oncodevelopmental Biology and Medicine. 2014; 35:379-385 ePub ahead of print DOI: 10.1007/ s13277-013-1053-z.

26. Jundt F, Anagnostopoulos I, Forster R, Mathas S, Stein H, Dorken B. Activated Notch1 signaling promotes tumor cell proliferation and survival in Hodgkin and anaplastic large cell lymphoma. Blood. 2002; 99:3398-3403.

27. Purow BW, Haque RM, Noel MW, Su Q, Burdick MJ, Lee J, Sundaresan T, Pastorino S, Park JK, Mikolaenko I, Maric D, Eberhart CG, Fine HA. Expression of Notch-1 and its ligands, Delta-like-1 and Jagged-1, is critical for glioma cell survival and proliferation. Cancer research. 2005; 65:2353-2363.

28. Cabrera CV. Lateral inhibition and cell fate during neurogenesis in Drosophila: the interactions between scute, Notch and Delta. Development. 1990; 110:733-742.

29. Fehon RG, Johansen K, Rebay I, Artavanis-Tsakonas S. Complex cellular and subcellular regulation of notch expression during embryonic and imaginal development of Drosophila: implications for notch function. The Journal of cell biology. 1991; 113:657-669.

30. Six E, Ndiaye D, Laabi Y, Brou C, Gupta-Rossi N, Israel A, Logeat F. The Notch ligand Delta1 is sequentially cleaved by an ADAM protease and gamma-secretase. Proc Natl Acad Sci U S A. 2003; 100:7638-7643.

31. Jung J, Mo JS, Kim MY, Ann EJ, Yoon JH, Park HS. Regulation of Notch1 signaling by Delta-like ligand 1 intracellular domain through physical interaction. Mol Cells. 2011; 32:161-165.

32. Kim MY, Jung J, Mo JS, Ann EJ, Ahn JS, Yoon JH, Park HS. The intracellular domain of Jagged-1 interacts with Notch1 intracellular domain and promo tes its degradation through Fbw7 E3 ligase. Exp Cell Res. 2011; 317:2438-2446.

33. LaVoie MJ, Selkoe DJ. The Notch ligands, Jagged and Delta, are sequentially processed by alpha-secretase and presenilin/gamma-secretase and release signaling fragments. J Biol Chem. 2003; 278:34427-34437.

34. Johnson DR, Sawyer AM, Meyers CA, O'Neill BP, Wefel JS. Early measures of cognitive function predict survival in patients with newly diagnosed glioblastoma. Neuro Oncol. 2012; 14:808-816.

35. Krex D, Klink B, Hartmann C, von Deimling A, Pietsch T, Simon M, Sabel M, Steinbach JP, Heese O, Reifenberger G, Weller M, Schackert G, German Glioma N. Longterm survival with glioblastoma multiforme. Brain. 2007; 130:2596-2606.

36. Chen J, Kesari S, Rooney C, Strack PR, Shen H, Wu L, Griffin JD. Inhibition of Notch Signaling Blocks Growth of Glioblastoma Cell Lines and Tumor Neurospheres. Genes Cancer. 2010; 1:822-835.

37. Kanamori M, Kawaguchi T, Nigro JM, Feuerstein BG, Berger MS, Miele L, Pieper RO. Contribution of Notch signaling activation to human glioblastoma multiforme. J Neurosurg. 2007; 106:417-427.

38. Fan X, Khaki L, Zhu TS, Soules ME, Talsma CE, Gul N, Koh C, Zhang J, Li YM, Maciaczyk J, Nikkhah G, Dimeco F, Piccirillo S, Vescovi AL, Eberhart CG. NOTCH pathway blockade depletes CD133-positive glioblastoma cells and inhibits growth of tumor neurospheres and xenografts. Stem Cells. 2010; 28:5-16.

39. Hovinga KE, Shimizu F, Wang R, Panagiotakos G, Van Der Heijden M, Moayedpardazi H, Correia AS, Soulet D, Major T, Menon J, Tabar V. Inhibition of notch signaling in glioblastoma targets cancer stem cells via an endothelial cell intermediate. Stem Cells. 2010; 28:1019-1029.

40. Gilbert CA, Daou MC, Moser RP, Ross AH. Gammasecretase inhibitors enhance temozolomide treatment of human gliomas by inhibiting neurosphere repopulation and xenograft recurrence. Cancer Res. 2010; 70:6870-6879.

41. Ulasov IV, Nandi S, Dey M, Sonabend AM, Lesniak MS. Inhibition of Sonic hedgehog and Notch pathways enhances sensitivity of CD133(+) glioma stem cells to temozolomide therapy. Molecular medicine. 2011; 17:103-112.

42. Wang Z, Li Y, Ahmad A, Azmi AS, Banerjee S, Kong D, Sarkar FH. Targeting Notch signaling pathway to overcome drug resistance for cancer therapy. Biochim Biophys Acta. 2010; 1806:258-267.

43. Bar EE, Lin A, Mahairaki V, Matsui W, Eberhart CG. Hypoxia increases the expression of stem-cell markers and promotes clonogenicity in glioblastoma neurospheres. The American journal of pathology. 2010; 177:1491-1502.

44. Jubb AM, Browning L, Campo L, Turley H, Steers G, Thurston G, Harris AL, Ansorge O. Expression of vascular Notch ligands Delta-like 4 and Jagged-1 in glioblastoma. Histopathology. 2012; 60:740-747. 
45. Yustein JT, Liu YC, Gao P, Jie C, Le A, Vuica-Ross M, Chng WJ, Eberhart CG, Bergsagel PL, Dang CV. Induction of ectopic Myc target gene JAG2 augments hypoxic growth and tumorigenesis in a human B-cell model. Proceedings of the National Academy of Sciences of the United States of America. 2010; 107:3534-3539.

46. Mullendore ME, Koorstra JB, Li YM, Offerhaus GJ, Fan X, Henderson CM, Matsui W, Eberhart CG, Maitra A, Feldmann G. Ligand-dependent Notch signaling is involved in tumor initiation and tumor maintenance in pancreatic cancer. Clinical cancer research : an official journal of the American Association for Cancer Research. 2009; 15:2291-2301.

47. Bland CE, Kimberly P, Rand MD. Notch-induced proteolysis and nuclear localization of the Delta ligand. J Biol Chem. 2003; 278:13607-13610.

48. Dyczynska E, Sun D, Yi H, Sehara-Fujisawa A, Blobel CP, Zolkiewska A. Proteolytic processing of delta-like 1 by ADAM proteases. J Biol Chem. 2007; 282:436-444.

49. Ikeuchi T, Sisodia SS. The Notch ligands, Delta1 and Jagged2, are substrates for presenilin-dependent "gammasecretase" cleavage. J Biol Chem. 2003; 278:7751-7754.

50. Simpson P. Notch signalling in development: on equivalence groups and asymmetric developmental potential. Curr Opin Genet Dev. 1997; 7:537-542.

51. Dell'albani P, Rodolico M, Pellitteri R, Tricarichi E, Torrisi SA, D’Antoni S, Zappia M, Albanese V, Caltabiano R, Platania N, Aronica E, Catania MV. Differential patterns of NOTCH1-4 receptor expression are markers of glioma cell differentiation. Neuro-oncology. 2014; 16:204-216.

52. Hulleman E, Quarto M, Vernell R, Masserdotti G, Colli E, Kros JM, Levi D, Gaetani P, Tunici P, Finocchiaro G, Baena RR, Capra M, Helin K. A role for the transcription factor HEY1 in glioblastoma. Journal of cellular and molecular medicine. 2009; 13:136-146.

53. Xu P, Yu S, Jiang R, Kang C, Wang G, Jiang H, Pu P. Differential expression of Notch family members in astrocytomas and medulloblastomas. Pathology oncology research : POR. 2009; 15:703-710.
54. Hu H, Zhou L, Awadallah A, Xin W. Significance of Notch1-signaling pathway in human pancreatic development and carcinogenesis. Applied immunohistochemistry \& molecular morphology : AIMM / official publication of the Society for Applied Immunohistochemistry. 2013; 21:242-247.

55. Ikemoto $T$, Sugimoto $\mathrm{K}$, Shimada M, Utsunomiya $\mathrm{T}$, Morine Y, Imura S, Arakawa Y, Kanamoto M, Iwahashi SI, Saito Y, Yamada S. Clinical Role of Notch Signaling Pathway in Intraductal Papillary Mucinous Neoplasm of the Pancreas. Journal of gastroenterology and hepatology. 2014; ePub ahead of print DOI: 10.1111/jgh.12660.

56. Mann CD, Bastianpillai C, Neal CP, Masood MM, Jones DJ, Teichert F, Singh R, Karpova E, Berry DP, Manson MM. Notch3 and HEY-1 as prognostic biomarkers in pancreatic adenocarcinoma. PloS one. 2012; 7:e51119.

57. Kolev V, Kacer D, Trifonova R, Small D, Duarte M, Soldi R, Graziani I, Sideleva O, Larman B, Maciag T, Prudovsky I. The intracellular domain of Notch ligand Delta1 induces cell growth arrest. FEBS Lett. 2005; 579:5798-5802.

58. Simon DP, Giordano TJ, Hammer GD. Upregulated JAG1 enhances cell proliferation in adrenocortical carcinoma. Clin Cancer Res. 2012; 18:2452-2464.

59. Galli R, Binda E, Orfanelli U, Cipelletti B, Gritti A, De Vitis S, Fiocco R, Foroni C, Dimeco F, Vescovi A. Isolation and characterization of tumorigenic, stem-like neural precursors from human glioblastoma. Cancer Res. 2004; 64:7011-7021.

60. Schreck KC, Taylor P, Marchionni L, Gopalakrishnan V, Bar EE, Gaiano N, Eberhart CG. The Notch target Hes 1 directly modulates Gli1 expression and Hedgehog signaling: a potential mechanism of therapeutic resistance. Clinical cancer research : an official journal of the American Association for Cancer Research. 2010; 16:6060-6070.

61. Krupka N, Strappe P, Gotz J, Ittner LM. Gatewaycompatible lentiviral transfer vectors for ubiquitin promoter driven expression of fluorescent fusion proteins. Plasmid. 2010; 63:155-160. 